\title{
Competencias mediáticas en docentes, base para la construcción de ciudadanía
}

institucional.us.es /ambitos/

\section{Jorge Abelardo Cortés Montalvo}

Universidad Autónoma de Chihuahua

jcortes@uach.mx

\section{Rigoberto Marín Uribe \\ Universidad Autónoma de Chihuahua \\ rimaur50@gmail.com

\author{
Isabel Guzmán Ibarra \\ Universidad Autónoma de Chihuahua \\ iguzman57@gmail.com
}

English Version: Mediatical competence among teachers, a fundament for the construction of the citizenship

\section{Resumen}

La posibilidad de contribuir a la construcción de ciudadanía en el afán de fortalecer un modelo de democracia participativa, así como entenderlos dispositivos de seducción de los medios de comunicación, descansa en buena medida, en desarrollar competencias críticas para la comprensión de la realidad social que se construye a partir del andamiaje mediático. Esta labor debe comenzar desde la escuela, en la competencia mediática y comunicativa de los profesores. Para los fines de este escrito, se han tomado como referente las competencias docentes del modelo M-DECA y se destaca un vector de competencia absolutamente

indispensable, de carácter genérico y transversal: la competencia comunicativa, fundamental en el proceso de construcción del aprendizaje, que se suele equiparar con el de 'adquisición de conocimiento'. Se propone un mecanismo de estructuración de componentes en secuencias didácticas, en actividades de aula, con el propósito de fortalecer la competencia mediática.

\section{Palabras clave}

Democracia, competencia mediática, docencia, ciudadanía.
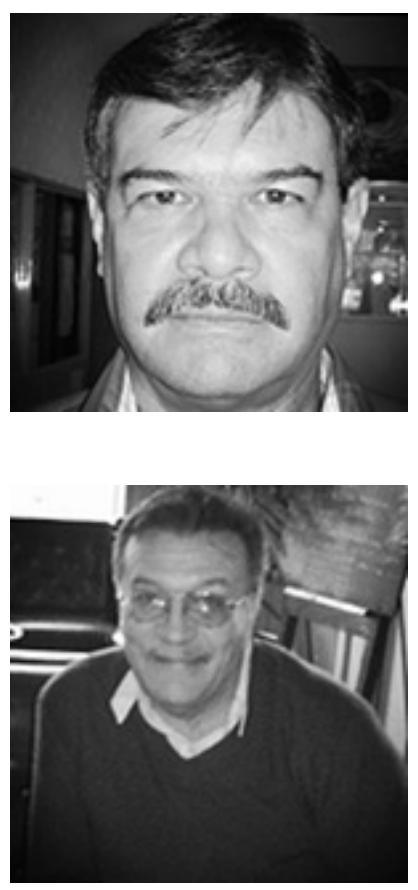

\footnotetext{
Abstract

The possibility of contribute to the construction of citizenship in the effort of strengthen an model of participative democracy, as well as to understand the devices of seduction of the media, lie in a good part on the development of the critical competences for the comprehension of the social reality that is built from the media framework. This labor has to start in the school, on the media and communicative competence of the teachers. For the purpose of this paper it had been use, as reference, the competences of the teachers that use the model M-DECA and stands

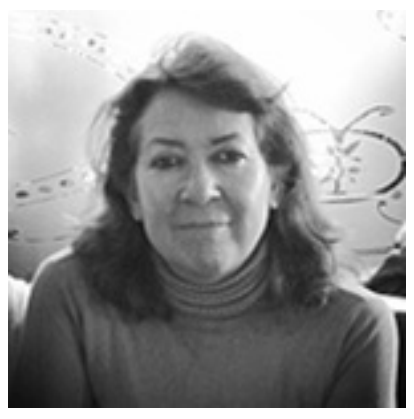
out a competence vector of absolute importance, of a generic and transverse nature: the communicative competence, fundamental on the process of construction of learning, which is usually provided with the 'acquisition of knowledge'. It is propose a mechanism of components organization in didactic sequences, in activities in the classroom, with the purpose of strengthen the media competence.
} 


\section{Keywords}

Democracy, media competence, teaching, citizenship.

\section{INTRODUCCIÓN}

La Educación para los medios va de la mano con la educación para la democracia, supone no solamente tener conocimiento de sus contenidos sino verdaderas competencias en su selección, interpretación, análisis crítico y construcción de mensajes propios. Los medios masivos de información, en general, son la primera ventana al entorno inmediato, cercano y distante, y en lo particular, es posible caracterizar conjuntos de audiencias que conforman su agenda temática y su visión de la realidad, a partir de la selección y preferencia de determinados medios; lectores de prensa escrita, audiencias de televisión, radioescuchas y usuarios de internet, casi siempre una combinación de ellos en diferente proporción.

El esfuerzo en este sentido, constituye un impulso a nivel global. Múltiples organismos internacionales tales como la Comisión Europea [i], la ONU a través de la Alianza para las Civilizaciones [ii], la OEA [iii], la UNICEF por medio del Desafío de Oslo [iv], entre otros, están cada vez más enfatizando la necesidad urgente de una educación mediática. Incluso se ha trabajado en la elaboración de instrumentos consensuados, como por ejemplo las Normas sobre competencias en TIC para docentes (UNESCO 2007) y el Currículo de alfabetismo en medios e información (AMI) para la formación de profesores [v] de la UNESCO (2011), la Carta Europea para la Alfabetización Mediática [vi] y el apoyo de la Alianza de las Civilizaciones en la Educación en Medios [vii], mediante congresos y publicaciones. En mayo del 2014, la UNESCO y la Comisión Europea celebraron en París, el I Foro European Media and Information Literacy para promover políticas tanto en Europa como globalmente que propongan la inclusión de la Competencia mediática en la educación formal, informal y en los grupos desfavorecidos, y el 10 y 11 de diciembre de 2014, ha sido México la sede donde se celebró el Foro Latinoamericano y del Caribe de Alfabetización Mediática e Informacional.

En lo que a México respecta, según el estudio realizado por el WIP-México (World Internet Project) [viii] en el 2012 llamado "Estudio de hábitos y percepciones sobre Internet y diversas tecnologías asociadas", existían en el país 52.3 millones de usuarios de internet, esto marcaba entonces una penetración de la red de un $46 \%$ en los mexicanos. Para el año 2013, ese mismo estudio arroja 59.2 millones de mexicanos con acceso a la red, ubicándose en el lugar 11 a nivel mundial respecto al número de usuarios de internet. El dato oficial, sin embargo, reconoce varios millones menos: según el Instituto Nacional de Estadística y Geografía (INEGI, 2013), en su estudio de "Encuesta en hogares sobre disponibilidad y uso de las tecnologías de la información", en el 2012 había 37.2 millones de mexicanos usuarios de internet, para el año 2013 existían 46 millones de usuarios. No obstante esta diferencia, el crecimiento es exponencial, lo que hace suponer que gradualmente se irá cerrando la brecha en cuanto a conectividad.

En cuanto al consumo de medios, el siguiente cuadro publicado por el Gabinete de Comunicación y Educación, con datos recogidos del 2012, puede dar una apreciación esquemática bastante precisa. 


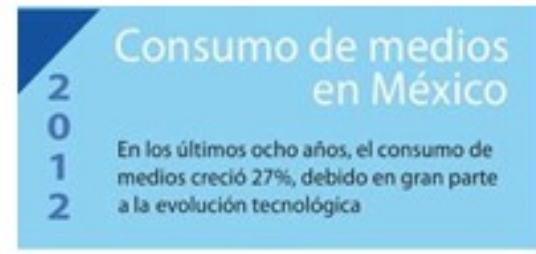

\section{Televisión}

El tiempo promedio de exposición al televisor en México es de mís de tres horas diarias
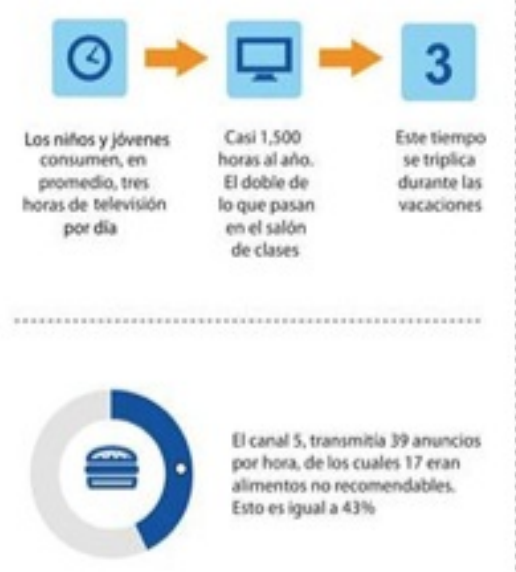

Radio

En Mexico, se escuchan en promedia, 11.1 horas de radio a la semana. Esto lo mundial por encima de Reino Unido y EU

\section{[E]}

En Mexco, laradio es el segundo medio de mayor pobliscion tiene acceso a 4 coloca en el ranking

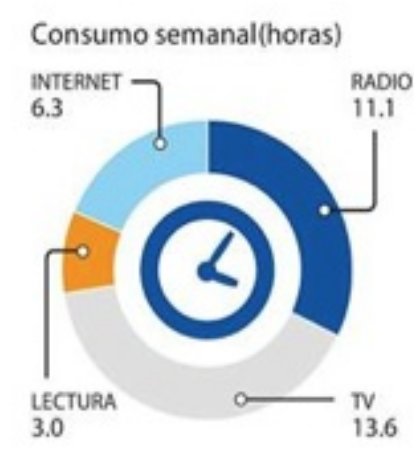

Lectura

Según datos del INEGI (2012), en México se invierten 3 horas de lectura por semana (esto incluye las lecturas escolares)

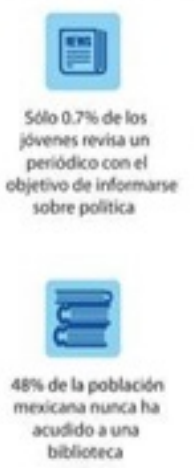

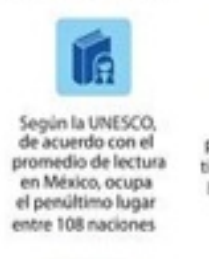
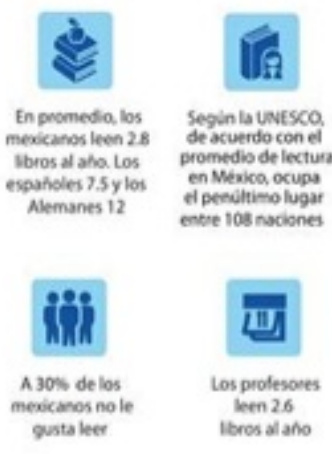
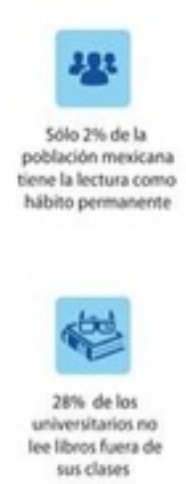

Internet

Los jovenes mayores de 16 años invierten en peomedilo, 13 horas en medios de comunicación masiva y solo 3.5 horas en actividades culturales, deportivas o de entretenimiento a la semana

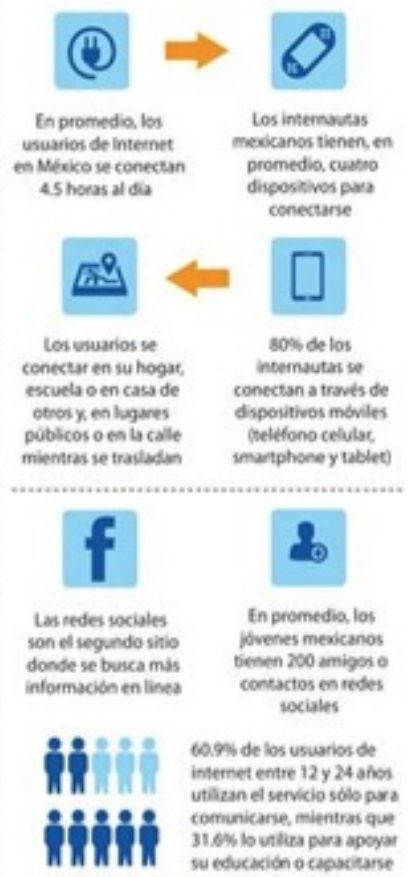

Fuente: http://www.gabinetecomunicacionyeducacion.com/noticias/

La definición de la competencia mediática, el desarrollo de planes de estudio y las evaluaciones son ya problemas universales que, como afirma Aguaded (2013), tratan cotidianamente organismos internacionales desde hace varios años y se sustentan en recomendaciones basadas en trabajos de investigación rigurosos. Las Recomendaciones del Parlamento Europeo en 2007 [ix], y de la Comisión Europea en 2009 [x], la Conferencia de Oriente Medio sobre la Educación en Medios en Arabia Saudita en el 2007, el Foro Internacional de Investigación sobre Medios (Londres; Hong Kong, 2008) o la Conferencia sobre Medios en África, celebrada en Nigeria también en 2008 son otros eventos internacionales que ratifican esta necesidad.

En México, lo más cercano a un organismo oficial de alfabetización digital, es la recientemente creada Coordinación General de Inclusión y Alfabetización Digital, denominada “@aprende.mx”, que apenas inicia operaciones. [xi] Creemos que la formación de ciudadanía descansa de manera muy especial en el desarrollo de la competencia comunicativa, particularmente en el ámbito mediático, esta inicia, desde luego, con acciones de alfabetización tecnológica, mediática e informacional y va de la mano con las fórmulas didácticas utilizadas por los profesores en el salón de clases.

\subsection{Competencias docentes y competencia comunicativa}

Las competencias han sido acomodadas en distintas clasificaciones y se han agrupado en múltiples categorías, se les suele subdividir en generales, específicas, particulares, o bien en estratos como básicos, superiores, especializados, macro o microcompetencias. También resulta complicado llegar a acuerdos acerca de cómo es posible evaluarlas o medirlas con suficiente exactitud, no obstante es conveniente poner en claro que, para su comprensión y estudio, "se le llama 'competencia', tanto a una estructura de ejecución compleja y precisa, como a una parte o secuencia de esta, o incluso, a un componente de dicha ejecución" (Cortés, Marín, \& Guzmán, 2013, p. 287). Lo importante, es identificar como se desempeña alguien competentemente frente a una situación determinada. (Jonnaert, Barrette, Masciotra, \& Yaya, 2008)

El Curriculum para la Alfabetización Mediática e Informacional (AMI) para profesores, (UNESCO, 2011), ha sido pensado precisamente para fortalecer en los profesores de todos los niveles el desarrollo de la competencia mediática, particularmente en el módulo uno (pp. 53-77), se dan recomendaciones para incorporar en primera 
instancia las nociones de ciudadanía, libertad de expresión e información, acceso a la información, discurso democrático y aprendizaje a lo largo de la vida. Otros autores (Reig, 2004) (Mancinas, 2008)han sugerido con anterioridad la importancia del papel que los medios pueden jugar en la construcción de ciudadanía y el tema ha sido abordado con posterioridad en consideraciones de carácter político (Mattelart, 2013) (Aceves, 2013).

En el diseño del modelo para el desarrollo y evaluación de competencias, (M-DECA), referido en específico a la actividad docente en el aula, Marín y Guzmán (2013) identifican, proponen y describen 7 competencias docentes: 1) Formación Continua, 2) Transposición didáctica, 3) diseño de la docencia, 4) Gestión de las competencias, 5) Interacción pedagógica, 6) Comunicación educativa y 7) Valoración del logro de las competencias. (tabla I)

En este modelo, las competencias docentes obedecen a una clasificación según su situación, donde pueden ser consideradas técnico-didácticas si se ubica su desarrollo en la fase de planificación; mientras que si se sitúa en la fase interactiva son clasificadas como comunicativas, pedagógicas y sociales respecto de las interacciones en clase, finalmente la fase postinteractiva agrupa las acciones de valoración del logro de las competencias en los estudiantes.

Tabla I Competencias docentes 


\begin{tabular}{|l|l|}
\hline Competencias & Descripción \\
\hline 1. Formación continua & $\begin{array}{l}\text { Gestiona el proceso de análisis, maduración y reflexión colegia } \\
\text { da de la docencia en la formación autónoma y responsable } \\
\text { para el logro de metas personales y profesionales. }\end{array}$ \\
\hline $\begin{array}{l}\text { 2. Transposición didácti } \\
\text { ca }\end{array}$ & $\begin{array}{l}\text { Conoce y se involucra en procesos colegiados para el fortaleci } \\
\text { miento del compromiso con la mejora y desarrollo de la } \\
\text { institución y su contexto educativo. De acuerdo con } \\
\text { Chevallard (1998, pág. 45) "Un contenido de saber que ha } \\
\text { sido designado como saber a enseñar, sufre a partir de } \\
\text { entonces un conjunto de transformaciones adaptativas } \\
\text { que van a hacerlo apto para ocupar un lugar entre los objetos } \\
\text { de enseñanza. El 'trabajo' que transforma de un objeto de } \\
\text { saber en un objeto de enseñanza, es denominado } \\
\text { transposición didáctica." }\end{array}$ \\
\hline 3. Diseño de la docencia \\
progresión de las & $\begin{array}{l}\text { Diseña su docencia con base en un modelo pedagógico que } \\
\text { parte de los contenidos y propósitos formativos de su materia; } \\
\text { considera la } \\
\text { postura que el profesor tiene sobre un modelo de docencia e } \\
\text { involucra métodos, medios y materiales de apoyo al desarrollo } \\
\text { y evaluación de competencias de los estudiantes. }\end{array}$ \\
\hline $\begin{array}{l}\text { Considera los itinerarios de formación y niveles de desempeño } \\
\text { en el logro de las competencias de los estudiantes; } \\
\text { asimismo, los observa y evalúa en situaciones } \\
\text { de aprendizaje y lleva a cabo controles periódicos para tomar } \\
\text { decisiones respecto a la progresión de las competencias. }\end{array}$ \\
\hline
\end{tabular}




\begin{tabular}{|l|l|}
\hline p.Interacción & $\begin{array}{l}\text { Practica una docencia basada en situaciones que considera la } \\
\text { puesta en } \\
\text { práctica de dispositivos, secuencias y de estrategias para el } \\
\text { desarrollo de competencias; implica también formas de } \\
\text { interacción para relación } \\
\text { educativa sustentada en una comunicación horizontal y } \\
\text { diseño de ambientes de aprendizaje que generen auténticas } \\
\text { redes de colaboración, así como los procesos de } \\
\text { evaluación formativa. }\end{array}$ \\
\hline 6.Comunicación \\
educativa12 & $\begin{array}{l}\text { Desarrolla cuatro microcompetencias instrumentales } \\
\text { íntimamente ligadas, encuadradas en una no instrumental de } \\
\text { carácter ético emocional: la competencia en la adquisición, } \\
\text { construcción y manejo interpersonal de lenguajes, la } \\
\text { competencia en utilización de tecnologías de información y } \\
\text { comunicación, como un recurso de apoyo a los procesos de } \\
\text { aprendizaje, la competencia en manejo de la información, la } \\
\text { cual promueve en los estudiantes la búsqueda, el manejo, } \\
\text { procesamiento e interpretación de la información y su } \\
\text { conversión en conocimiento, la competencia en medios, con la } \\
\text { cual se busca que adopte una posición } \\
\text { crítica frente a los medios y sea capaz de colocar } \\
\text { conocimiento en los circuitos de información. }\end{array}$ \\
\hline $\begin{array}{l}\text { Aplica dispositivos, estrategias e instrumentos para la evaluaci } \\
\text { ón del logro de las competencias de sus estudiantes, } \\
\text { la acreditación de la materia, la satisfacción de las } \\
\text { expectativas del profesor y de los } \\
\text { estudiantes, así como la valoración del impacto } \\
\text { personal de la experiencia didáctica. }\end{array}$ \\
\hline
\end{tabular}

Fuente: tomado de M-DECA (Marín \& Guzmán, 2013)

Para los fines del presente ensayo, se ha tomado este modelo como paradigma de competencias docentes, dos de ellas, la transposición didáctica y la interacción pedagógica, aunque de franco contenido comunicativo, son concebidas en este esquema desde la perspectiva del trabajo profesoral, como se ha señalado, al interior del aula y se resalta y complementa la sexta competencia descrita en virtud de que entre todas las posibles categorías, destaca un vector de competencia absolutamente indispensable, de carácter genérico y transversal, que comprende todos los aspectos relacionados con la problematización, la contextualización, la identificación de materiales manipulables, y desde luego, la interacción. Nos referimos a la competencia comunicativa, fundamental en el proceso de construcción del aprendizaje, que solemos equiparar con el de 'adquisición de conocimiento', así mismo y en el marco comunicacional, es posible encuadrar a la trasposición didáctica y a la 
interacción pedagógica, sin que pierdan su carácter específico de competencias docentes, como elementos integrados e interactuantes en la competencia comunicativa.

A este respecto, es pertinente hacer un apunte epistemológico: El enfoque por competencias conlleva un sentido de tipo eminentemente pragmático, es decir, se orienta a la solución de problemas o al alcance de metas y objetivos. Todo contenido tiene un carácter esencial de dato, de información, que se convertirá en conocimiento si y solo si, resuelve una situación problema, o se vuelve la llave para alcanzar un objetivo o propósito específico. Lo que llamamos 'conocimiento', suele ser la identificación y ordenación provisional de secuencias de hechos asociados a determinados fenómenos, integradas en un cuerpo de representaciones complejas de vigencia variable (Cortés, Marín, \& Guzmán, 2013, p. 288)

Las competencias no se transmiten o se enseñan; se desarrollan y se perfeccionan, según apunta Inés Aguerrondo (2009) "hoy sabemos que el alumno no es un objeto de enseñanza sino un sujeto de aprendizaje, y también sabemos que 'enseñar' es organizar experiencias de aprendizaje para que el alumno avance en su proceso de construcción del objeto de aprendizaje". En el aula se adquieren conceptos, teorías, habilidades, técnicas; se aprende a usar herramientas, a aplicar fórmulas a ensayar soluciones. Desde luego, todo eso sirve, y mucho, para desarrollar competencias, las cuales se manifiestan en el momento preciso en que hace falta poner en juego selectivamente todo lo aprendido y ensayado, y aún reaprender, acomodar, recuperar e incorporar nuevos aprendizajes, calibrar desempeños y manejar la experiencia como fallida o satisfactoria, para redondear o completar la competencia.

El modelo de competencias también puede recibir la crítica de que obedece a un sistema que ve a la población estudiantil como -todavía- incompetente, o utilizando como símil la expresión de Martín Echeverría, refiriéndose a la pobreza, "como individuos disfuncionales, incapaces de adaptarse satisfactoriamente al sistema económico y que necesitan ser rehabilitados y transformados en actores sociales funcionales" (Echeverría, 2014, p. 87) y en lo que respecta al sector docente, como miembros de comunidades educadas, los profesores preservan un horizonte de interpretación social similar al de los medios de difusión; incluso sus opiniones y puntos de vista dependen en buena medida de las representaciones elaboradas por los informativos, tanto por la alineación editorial como por la dependencia que tienen a los referentes descritos por la prensa misma.

\subsubsection{Competencia Mediática}

Se reconoce que la competencia comunicativa es la confluencia de varios ámbitos de competencias (UNESCO, 2011), que tienen que ver desde luego con la adquisición y uso del lenguaje pero también con el manejo de información (infocompetencia), de instrumentos y dispositivos tecnológicos (tecnocompetencia) y sin duda, con los medios (mediacompetencia) (Fig. 1). Estos cuatro ámbitos de tipo instrumental, contenidos en un ámbito no instrumental de carácter 'ético-emocional', también denominado por Gabelas, Marta y Helguera (2012) como Factor Relacional (F'R'). 


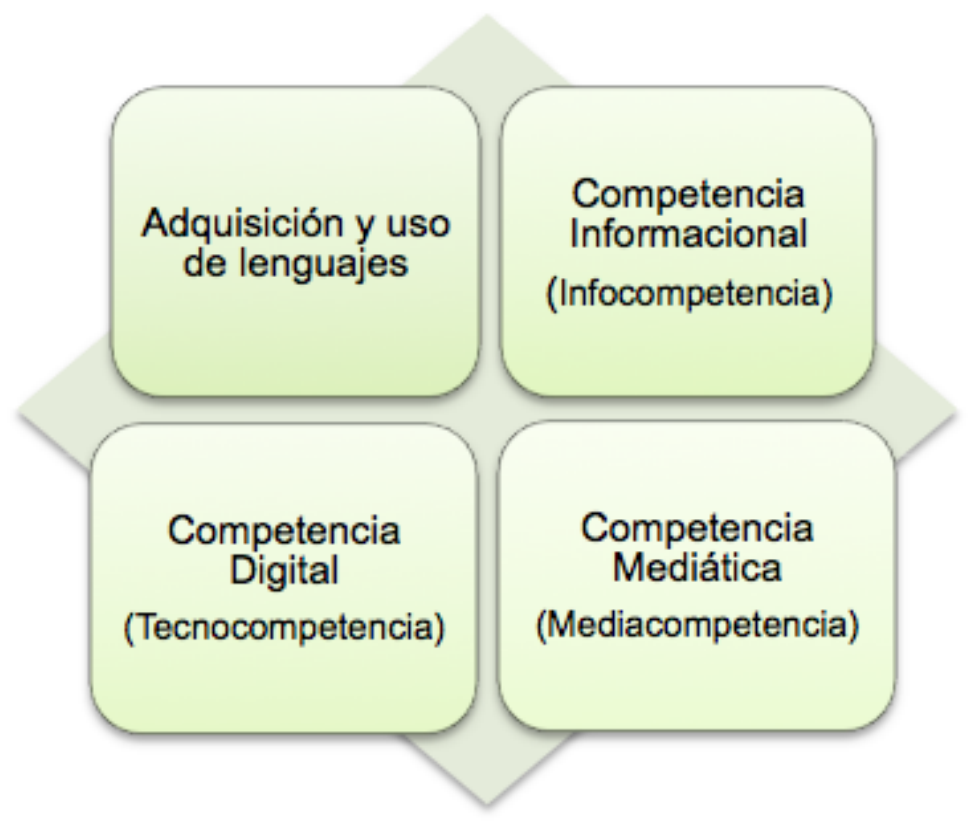

Fig.1 COMPETENCIA COMUNICATIVA (Ámbitos instrumentales de la competencia comunicativa, el rombo central representa el ámbito no instrumental de carácter ético-emocional-relacional, Factor " $R$ " que los contiene)

También se ha sugerido que hay niveles de ejecución que van desde los dominios o 'alfabetismos' elementales, hasta los de alta competencia, los propiamente creativos capaces de generar innovaciones y producir conocimiento (Cortés \& Carrillo, 2012, p. 261).

Desde luego en cada ámbito es posible reconocer ejecuciones (performance) específicas pero nos interesa destacar aquí la competencia mediática en los docentes, de acuerdo con las categorías o dimensiones mencionadas, para ello nos valemos del siguiente esquema: (Fig. 2)

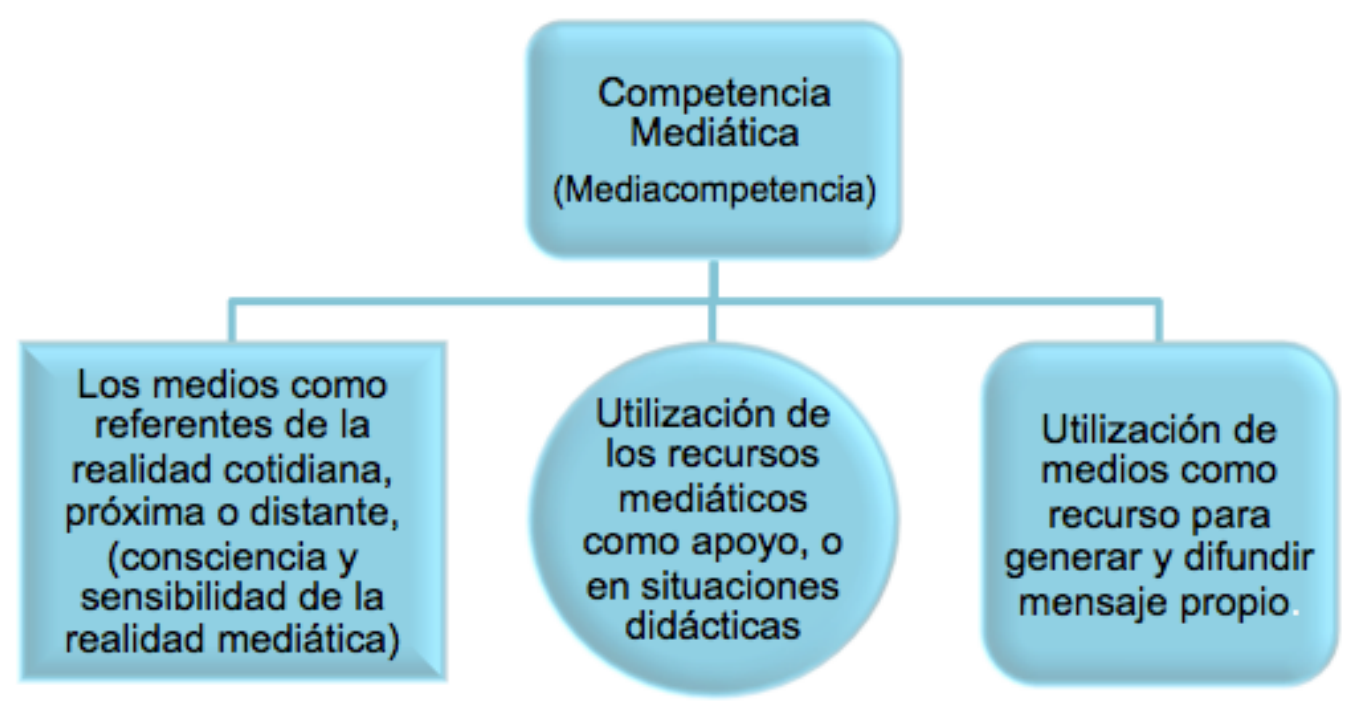

\section{Fig. 2 Competencia mediática en docentes.}

De entre los diferentes ámbitos identificables en la competencia comunicativa, se destaca la parte relacionada con la agenda que marcan las informaciones vertidas por los medios masivos de información y comunicación, en realidad los circuitos convencionales y virtuales que funcionan a manera de "ventanas al mundo", donde las personas se enteran de lo destacado por esos mismos circuitos acerca de su entorno, inmediato y mediato; local y en otros confines geográficos. Se refiere a la Identificación, por parte tanto del estudiante como del profesor, de las características de tales medios y canales por los cuales viaja la información, los códigos en que se cifran los 
mensajes, los formatos en que se enmarcan, sus esquemas de 'seducción' y disuasión y las estructuras que adoptan en los modos de construir o representarse la realidad. El profesor es competente cuando 'adquiere conciencia' y se visualiza y asume como mediador del conocimiento.

Ferrés \& Pisticelli (2012, pág. 79) definen la competencia en medios como:

La capacidad de un individuo para interpretar y analizar, desde la reflexión crítica las imágenes y los mensajes audiovisuales y para expresarse con una mínima corrección en el ámbito comunicativo. Esta competencia está relacionada con los medios de comunicación y con el uso básico de las tecnologías multimedia necesarias para producirla.

Comprende así mismo la capacidad de construir mensajes propios e identificar los mecanismos de colocación en los diferentes sistemas de circulación. Es decir, la generación de nueva información traducida en productos tangibles (documentos en cualquier formato) y su puesta en circulación en algún circuito de difusión.La competencia mediática comprende adicionalmente, en el caso de los profesores, la selección y utilización de medios diversos para la aplicabilidad de los productos de conocimiento generado, en alguno o varios de los contextos o escenarios siguientes:

- En sus asignaturas frente a grupo en el salón de clases

- En sus cursos en modalidad virtual o, en su caso, en MOOC's [xiii]

- En sus proyectos y actividades fuera del aula, con redes o grupos de trabajo o de investigación y en comunidades de aprendizaje.

- En la solución de problemas en el entorno personal, productivo, económico o social.

- En el análisis crítico de las fuentes que le permiten la percepción de su realidad local, nacional y mundial.

Tal argumentación, permite vincular la mayor o menor competencia mediática de los profesores, con la estructuración de secuencias didácticas en su actividad docente, que parten del planteamiento de situaciones problema extraídas precisamente de la "realidad mediática", para generar aprendizajes significativos a fin de desarrollar competencias que puedan ser puestas en práctica en situaciones reales de integración o, en términos de Roegiers (2010), en familias de dichas situaciones. Utilizando las palabras de Echeverría (2014, p. 83) aplicadas a los profesores, en primer lugar:

... concentran poder simbólico en un ámbito institucional, pues al dirigirse a una audiencia - grupo de alumnosdesprovista de una capacidad equiparable de comunicación pública, se establece de manera estructural una asimetría de recursos simbólicos y de manera consecuente, la potencialidad de definir una parcela de la realidad social para los demás actores. En segundo lugar definen realidades objetivas para los receptores, pues su capacidad de darle sentido a la información y de proporcionar las explicaciones -causas y consecuencias- de los hechos provee una oportunidad para definir la naturaleza de los temas e influenciar cognitivamente a los estudiantes.

También es cierto que hay que enseñar con el ejemplo y que es conveniente marcar la diferencia entre aprender 'sobre' los medios y aprender 'a través' de estos, por ello, el profesor competente organiza sus actividades de aprendizaje echando mano de buena parte de esta competencia, en síntesis, a partir de tres categorías o dimensiones: Conciencia y sensibilidad de la realidad de los medios, utilización de recursos mediáticos como apoyo didáctico en el aula, y utilización de los medios para generar y difundir mensajes propios. La tabla II puntualiza algunos elementos deseables comprendidos en la competencia mediática de profesores:

Tabla II Elementos de la competencia mediática en docentes

\section{COMPETENCIA MEDIÁTICA}

\begin{tabular}{|l|l|l|}
\hline Categorias/Dimensiones & Descripción & Atributos/Indicadores \\
\hline Conciencia y & Capacidad de & Busca, recupera y analiza
\end{tabular}




\begin{tabular}{|c|c|c|}
\hline $\begin{array}{l}\text { sensibilidad de la } \\
\text { realidad de los medios }\end{array}$ & $\begin{array}{l}\text { búsqueda, } \\
\text { recuperación y análisis } \\
\text { activo y crítico de la } \\
\text { información en la oferta } \\
\text { televisiva, periodística, } \\
\text { radiofónica, en la red } \\
\text { virtual y en general, } \\
\text { mediática. } \\
\text { Conversión de un } \\
\text { elemento pasivo de un } \\
\text { segmento de audiencia } \\
\text { en un receptor crítico } \\
\text { de los mensajes } \\
\text { mediáticos, tanto } \\
\text { noticiosos, como } \\
\text { publicitarios y de } \\
\text { entretenimiento. }\end{array}$ & $\begin{array}{l}\text { críticamente información de los } \\
\text { medios de comunicación masiva, } \\
\text { tanto convencional como digital. } \\
\text { Detecta y explica las tendencias y } \\
\text { propuestas ideológicas y } \\
\text { axiológicas en la información } \\
\text { proporcionada por los medios } \\
\text { Identifica los diferentes tipos de } \\
\text { mensaje y señala los intereses } \\
\text { implícitos que hay en ellos } \\
\text { Reconoce y señala en los } \\
\text { mensajes mediáticos las técnicas } \\
\text { para su construcción y los } \\
\text { elementos creativos para captar } \\
\text { su atención } \\
\text { Elabora juicios de valor sobre el } \\
\text { contenido e intención de los } \\
\text { mensajes y la fuente. }\end{array}$ \\
\hline $\begin{array}{l}\text { Utilización de recursos } \\
\text { mediáticos como apoyo } \\
\text { didáctico en el aula }\end{array}$ & $\begin{array}{l}\text { Destreza para integrar } \\
\text { a los contenidos } \\
\text { programáticos de } \\
\text { carácter académico o } \\
\text { curricular, el recurso } \\
\text { de los medios de } \\
\text { comunicación, } \\
\text { en la actividad escolar } \\
\text { y docente }\end{array}$ & $\begin{array}{l}\text { Integra en sus actividades } \\
\text { formativas elementos mediáticos } \\
\text { como apoyo del proceso de } \\
\text { aprendizaje } \\
\text { Analiza situaciones problema y } \\
\text { de integración a partir de la } \\
\text { construcción de la realidad social } \\
\text { configurada en la información de } \\
\text { los medios } \\
\text { Relaciona los temas de } \\
\text { aprendizaje con situaciones } \\
\text { planteadas en contextos de la } \\
\text { realidad mediática }\end{array}$ \\
\hline
\end{tabular}




\begin{tabular}{|c|c|c|}
\hline $\begin{array}{l}\text { Utilización de los } \\
\text { medios para generar y } \\
\text { difundir mensajes } \\
\text { propios }\end{array}$ & $\begin{array}{l}\text { Capacidad para } \\
\text { identificar las pautas de } \\
\text { la agenda en medios } \\
\text { convencionales y de la } \\
\text { red de Internet y las } \\
\text { estrategias para su } \\
\text { difusión masiva a } \\
\text { través de redes } \\
\text { sociales, aplicaciones y } \\
\text { dispositivos móviles o } \\
\text { celulares. } \\
\text { Habilidad para crear y } \\
\text { generar sus propios } \\
\text { mensajes y situarlos en } \\
\text { los circuitos de difusión } \\
\text { en los diferentes } \\
\text { medios. }\end{array}$ & $\begin{array}{l}\text { Identifica y señala los temas } \\
\text { relevantes de la agenda } \\
\text { informativa y los relaciona con la } \\
\text { priorización de temas en la } \\
\text { agenda económica, política y } \\
\text { cultural de su comunidad } \\
\text { Utiliza los recursos mediáticos } \\
\text { para la construcción y corrección, } \\
\text { textual y audiovisual, en la } \\
\text { elaboración de mensajes } \\
\text { intencionales de contenido } \\
\text { diverso } \\
\text { Genera documentos, a partir de } \\
\text { sus búsquedas de información, } \\
\text { tareas o investigaciones, en } \\
\text { cualquier formato y los coloca en } \\
\text { diferentes circuitos mediáticos }\end{array}$ \\
\hline
\end{tabular}

Fuente: Elaboración propia.

En cuanto a la primera categoría, los medios son el referente más conspicuo de la realidad cotidiana, bien en la propia localidad o en el confín más distante, la consciencia de la conformación de dicha realidad a partir de los retazos que recogen, editan y distribuyen los medios de comunicación, se encontrarían en docentes mediáticamente competentes, tanto en lo referido a su sensibilidad para detectar las fuentes a través de las cuales construye su percepción de la realidad social, que es común a cualquier persona mediáticamente competente, como aquellos que se desprenden de la aplicación de este conocimiento en sus actividades áulicas, didácticas o propiamente docentes.

De manera específica en la referencia de Eduteka [xiv] se hacen constar los cinco conceptos básicos y las preguntas clave para ser alfabeta mediático, que llevado a sus niveles de competencia debería comportarse como se muestra en la figura 3 : 


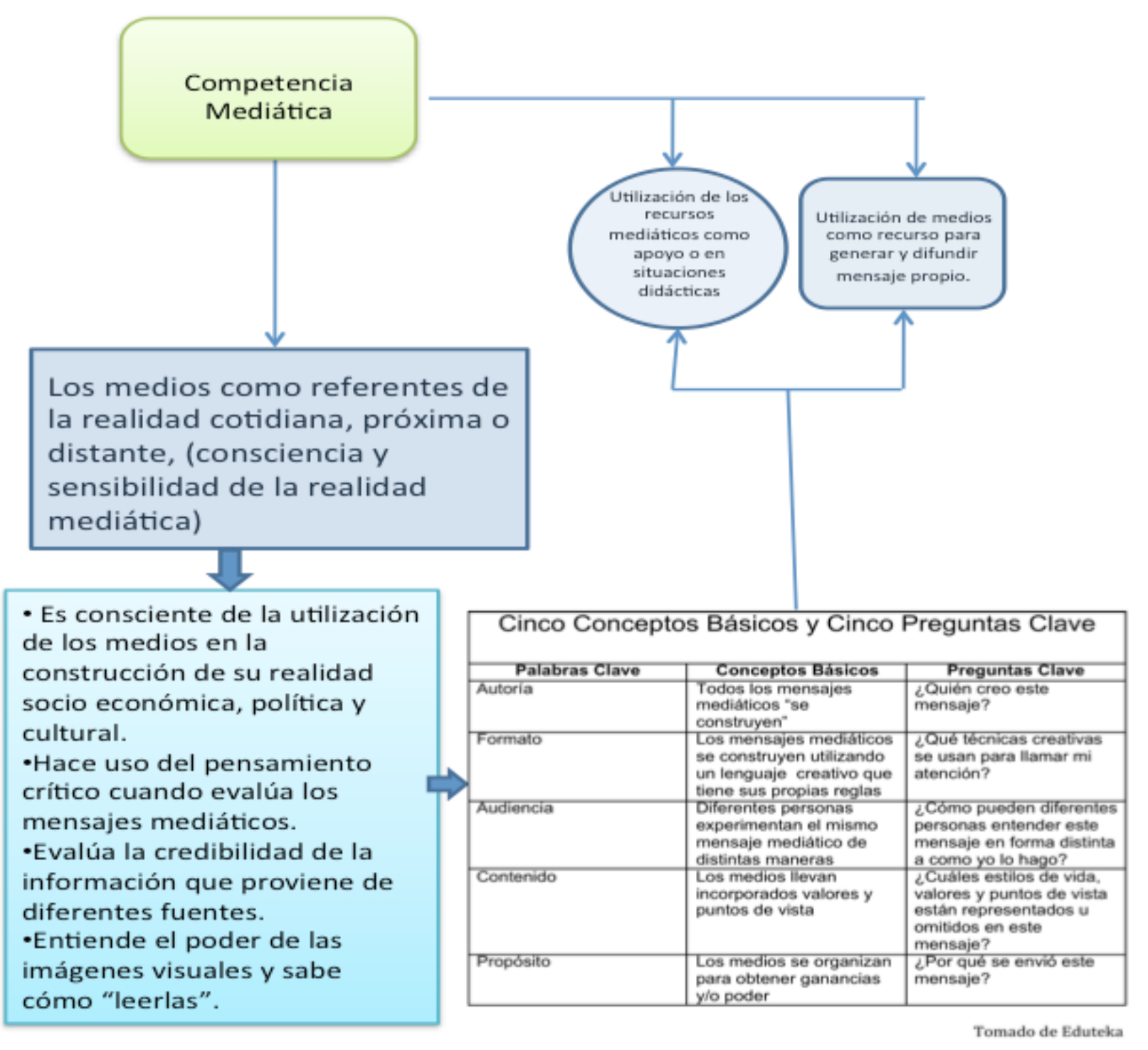

Fig. 3 Conciencia y sensibilidad de la realidad mediática

La segunda dimensión o categoría del docente mediáticamente competente, se refiere a estar en condiciones de utilizar la información recuperada de los medios, críticamente analizada, para diseñar secuencias didácticas de aprendizaje. Esencialmente, según describe el modelo M-DECA, un diseño de aprendizaje adecuado para un proceso formativo consta de, al menos, tres componentes: una situación problema, es decir una "situación de la realidad que obliga a intervenir y cuestiona o plantea problemas para resolver" (Zabala \& Arnau, 2007); una secuencia didáctica que describe las competencias por alcanzar, las actividades de aprendizaje y los criterios de evidencia que el alumnado debe demostrar, y una situación de integración, que es el retorno a una condición de realidad donde se pone en práctica lo aprendido y se incorpora dicha práctica al desarrollo y perfeccionamiento de competencias.

Para tal propósito, se echa mano del concepto de 'trasposición didáctica', esto es, la transformación del saber erudito en objeto de enseñanza o saber enseñado (Chevallard, 1998) o de material de aprendizaje. La combinación de estos tres elementos conduce al aprendizaje significativo y es su cualidad de aplicación a la solución de problemas reales lo que le da, precisamente, su significatividad. El proceso se ilustra en la figura 4: 


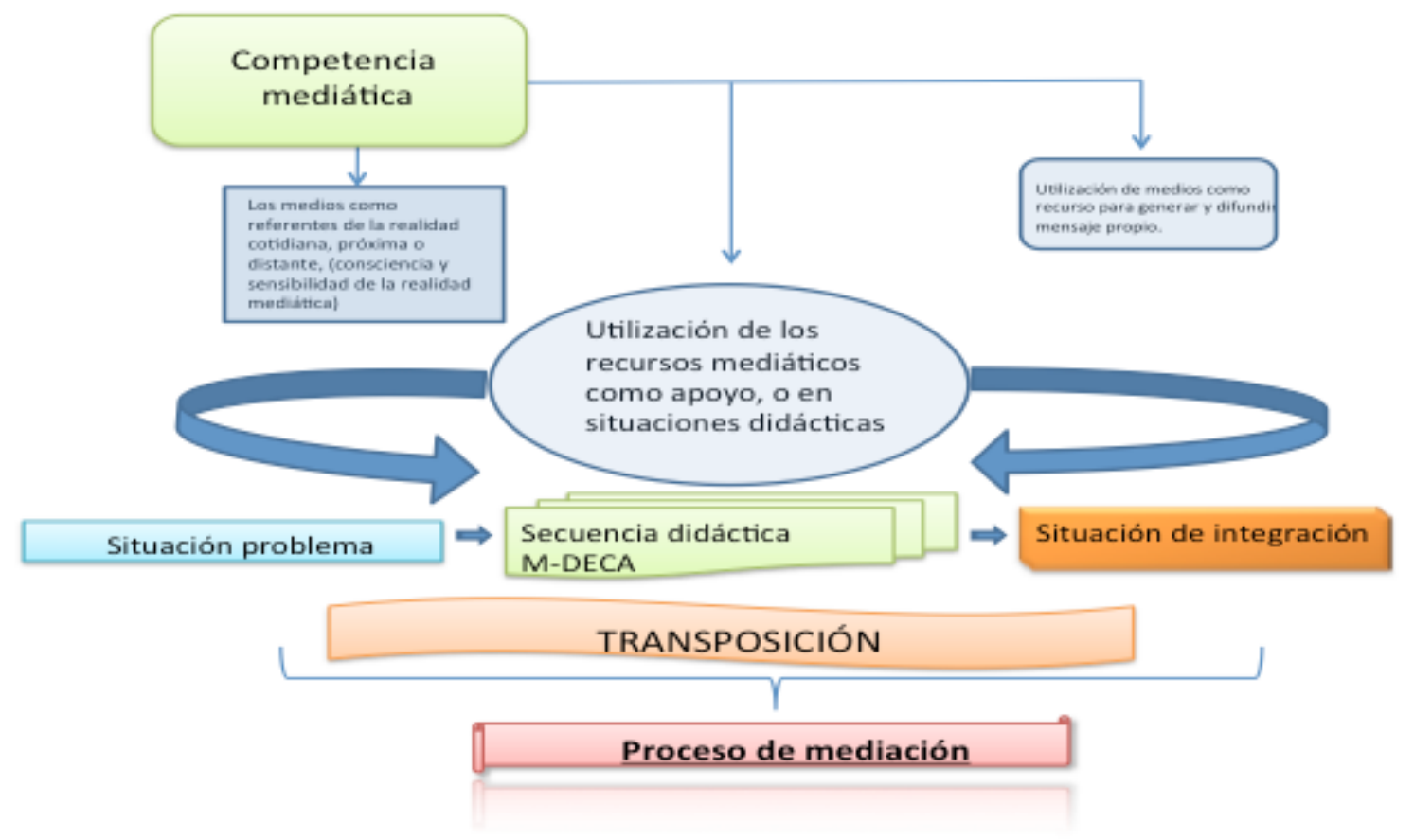

Fig. 4 Formación pedagógica y construcción de ciudadanía

Cuando se habla de educación y de construcción de ciudadanía, es conveniente establecer la diferencia, sin duda nada sutil, en el desarrollo de la competencia mediática entre párvulos o estudiantes de nivel básico, más cercanos a los procesos pedagógicos, y entre estudiantes universitarios, en procesos mayormente andragógicos, dado que los intereses de unos y otros son distintos y la exposición a diversos contextos y exigencias sociales, también difieren enormemente.

Los niños están típicamente expuestos y prestan mayor atención al bombardeo de la publicidad más que a la construcción de una visión del mundo y del entorno socioeconómico en el que se focalizan en mayor medida jóvenes y adultos; el profesor de niveles básicos, en la elaboración de sus secuencias didácticas, puede perfectamente incorporar 'situaciones problema' recuperadas de la información en medios, por ejemplo: "México ocupa uno de los primeros lugares mundiales en obesidad infantil, lo cual trae múltiples problemas de salud" [xv]. Enseguida diseñar dispositivos de aprendizaje sobre una adecuada nutrición, diferenciando entre otras cosas los alimentos 'chatarra', golosinas y refrescos, de aquellos que contienen nutrientes necesarios para el organismo. Generar luego una 'situación de integración' acudiendo de nuevo a los medios, pero en este caso revisando detenida y críticamente la publicidad, de modo que el niño identifique y descubra las intenciones de los comerciales y los recursos que se utilizan para disuadirlo a consumir así como las consecuencias posibles. (Fig. 5) 


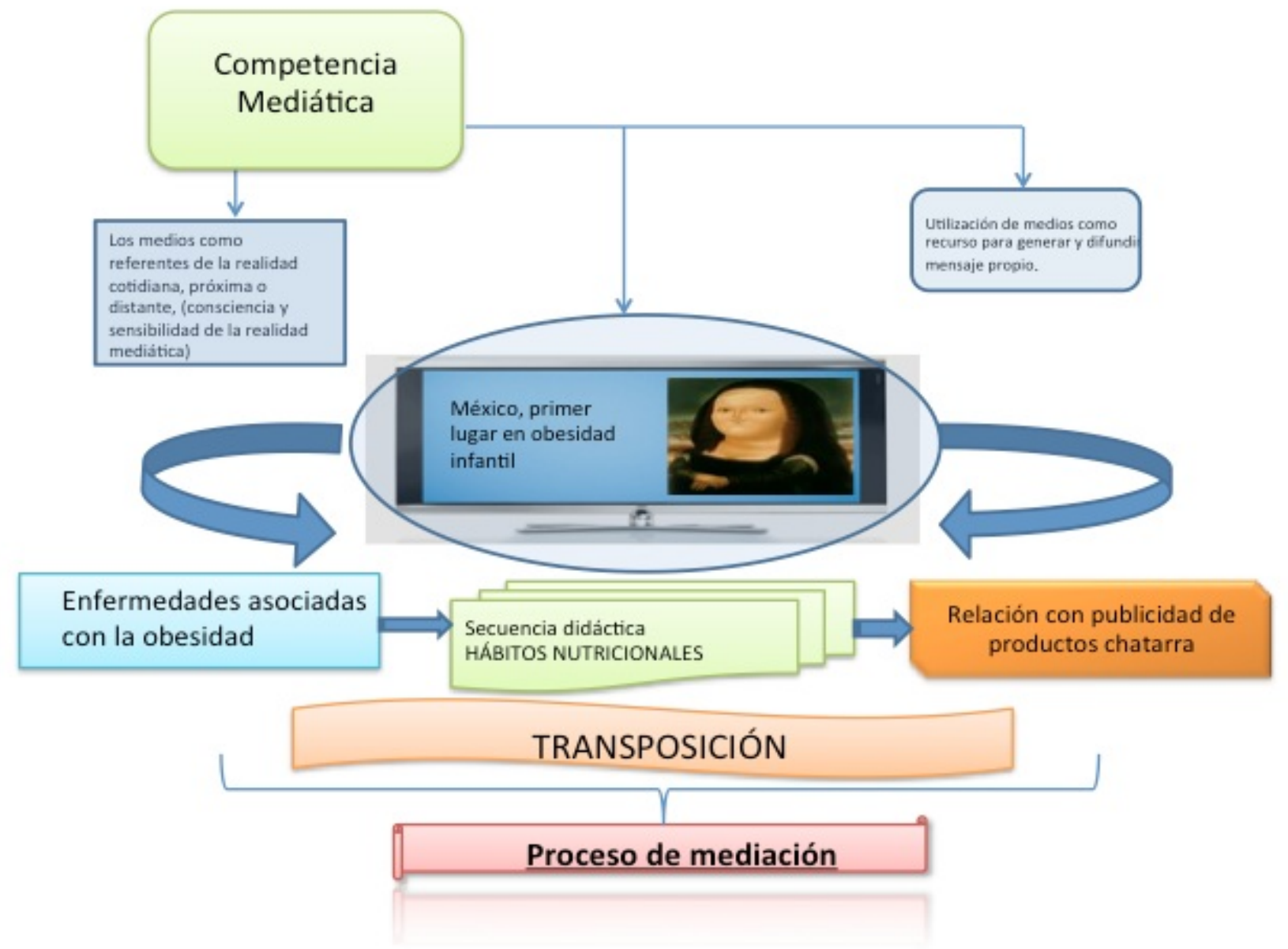

\section{Fig. 5 Ejemplo de una secuencia pedagógica}

En el proceso de construcción de ciudadanía, es menester romper con rezagos, inercias y ataduras que se han mantenido como estrategias educativas.

Introducir el pensamiento crítico (Paul \& Elder, 2007)en el análisis de la información política que proporcionan los medios en secuencias didácticas de aprendizaje, con el fin de crear y recrear condiciones para el desarrollo de la competencia mediática, que debe ser común a cualquier estudiante, bien podría ser tarea cotidiana en las asignaturas básicas que conforman los programas académicos en educación media y superior. Los docentes, generalmente formados como profesionistas, no como profesores, desde luego deberán contar con la competencia y una preparación didáctica en el diseño de tales secuencias para su implementación como proceso mediador.

A manera de ejemplo, un análisis básico que se debería seguir en la información, es el tratamiento que los medios dan a la responsabilidad civil y a los derechos de los ciudadanos (secuencia didáctica de aprendizaje), de modo que se evidencie como el trabajo de los funcionarios en las distintas esferas y niveles de poder contribuye a fortalecer el tejido social. Para ello, habría que situar bajo análisis crítico, cómo la espectacular y a veces tenebrosa agenda de los informativos, fincada en la violencia recurrente, la inseguridad y la impunidad, que mantiene una inquietud generalizada (situación problema), podría ser resuelta, o al menos paliada con las reformas acordadas entre los poderes (situación de integración).

La figura 6 ejemplifica el tratamiento de la información en una secuencia de aprendizaje, partiendo del análisis crítico de los medios y llevado a asuntos públicos. 


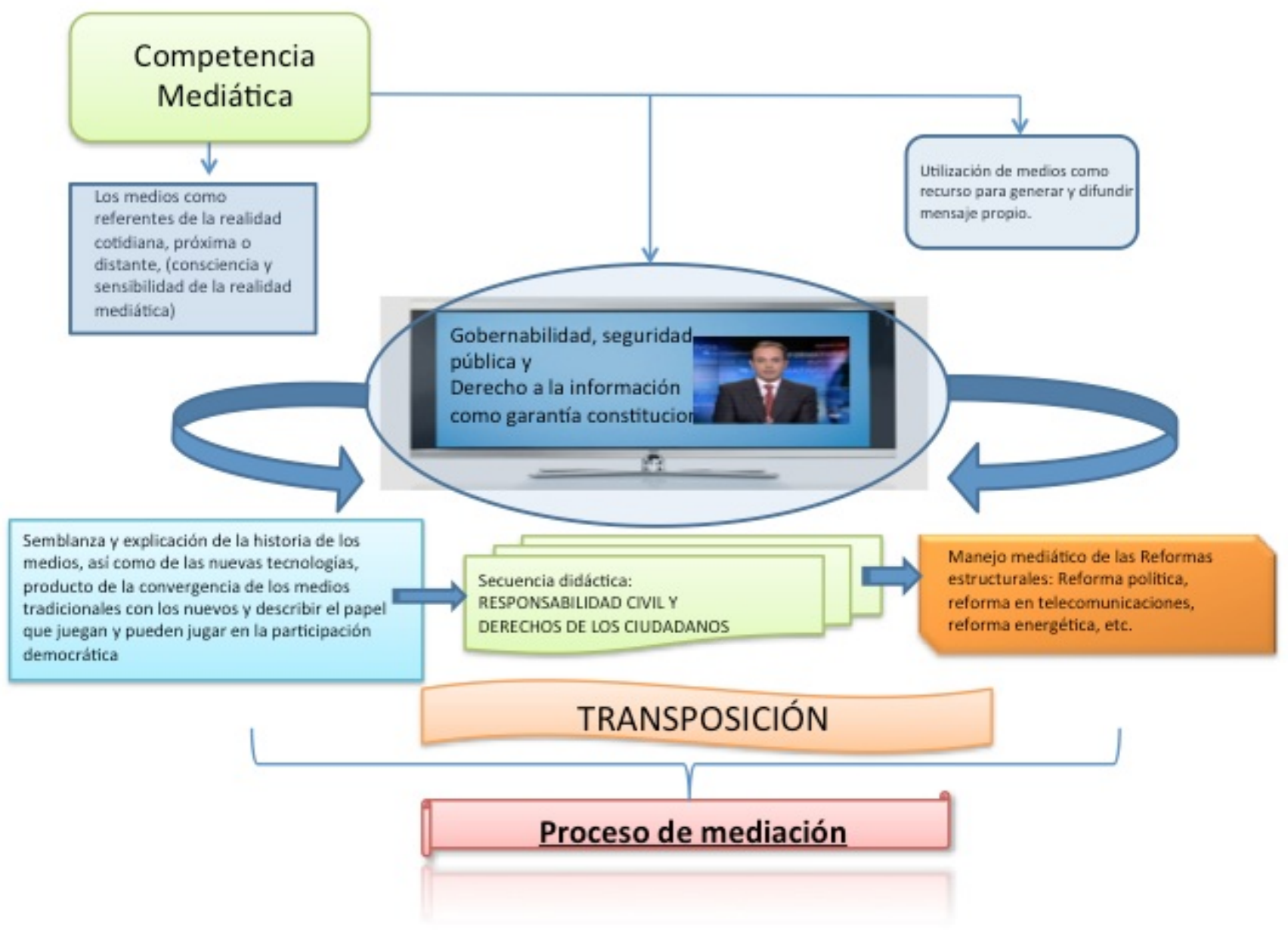

\section{Fig. 6 Secuencia de aprendizaje del tratamiento de asuntos políticos en los medios}

Otro ejemplo que se expresa en la figura 7, es el referido al ejercicio de la democracia y la participación de los medios en la difusión de plataformas político electorales, a través de la promoción de partidos y candidatos por medio de la publicidad y principalmente, de la propaganda. En este caso, la situación problema es identificar las características, semejanzas y diferencias entre democracia representativa y democracia participativa, y analizar las herramientas políticas que necesita el ciudadano para el ejercicio de una y otra. A partir del análisis del mensaje mediático en clave de propaganda o campaña política, se tratará de identificar cuáles y cuántas de dichas herramientas están, efectivamente disponibles para que los ciudadanos ejerzan su derecho. 


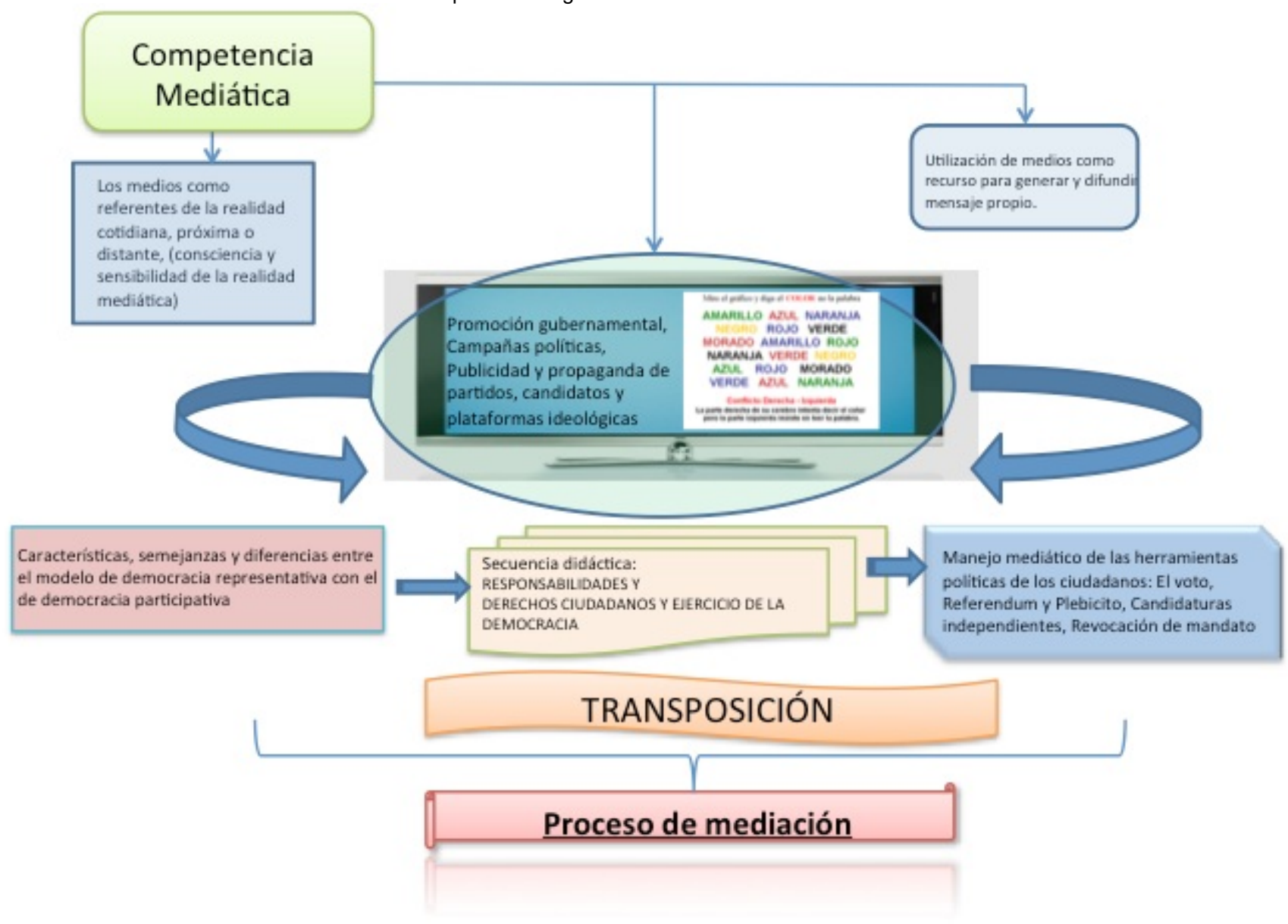

Fig. 7 Secuencia de aprendizaje del ejercicio político y democrático en los medios

La tercera categoría se refiere a la utilización de los medios como vehículo para generar y difundir mensajes propios. En este apartado se consideran aspectos tales como el derecho a la comunicación y la libre expresión de las ideas, así como la apertura de espacios para que los docentes y los estudiantes estén en condiciones de utilizar los medios convencionales, electrónicos y la red de internet (medio que es el más interactivo, con aplicaciones diversas tales como Instagram, redes sociales, Whatsapp, blogs, creative commons, etc.), para colocar trabajos, argumentos, opiniones, reflexiones de sus experiencias de clase, resultados de sus investigaciones y en general, productos documentados resultantes de sus tareas académicas, esto es, mensajes propios, que además se puede hacer desde muy variados dispositivos. Dicha práctica sin duda genera en los docentes importantes beneficios agregados. (Fig. 8) 


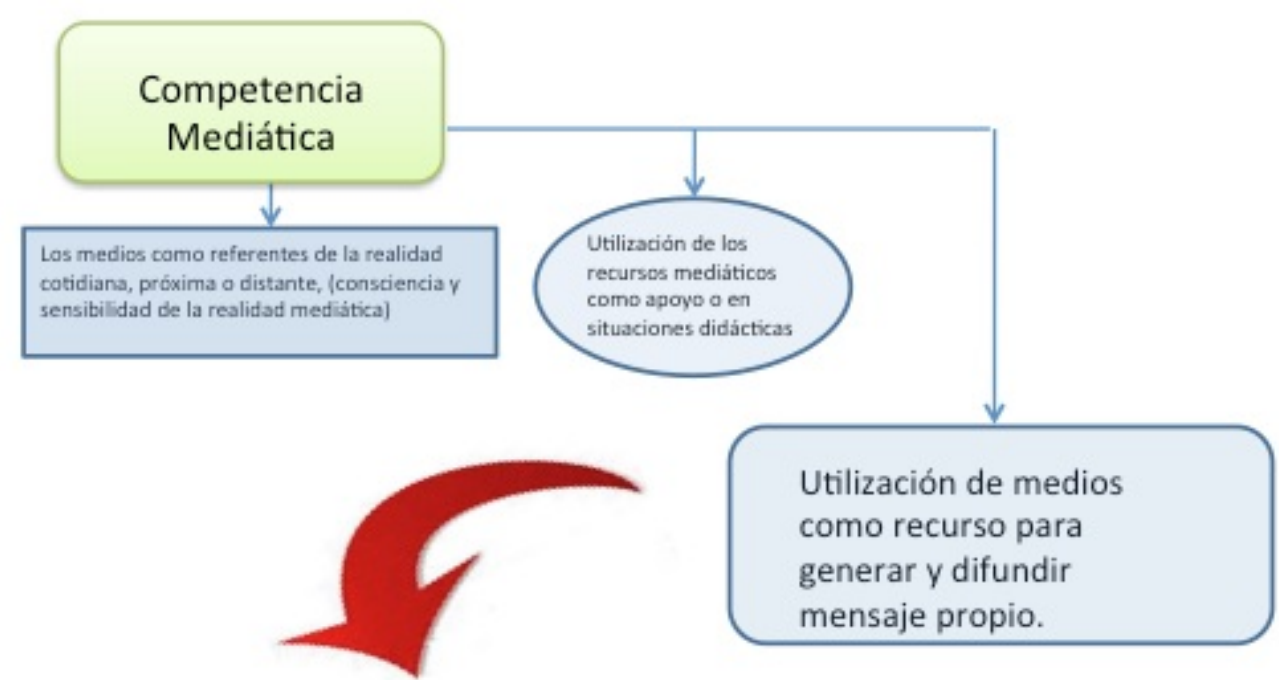

-Reflexión sobre su propia práctica

$\Rightarrow$ Documenta y genera productos de conocimiento, sobre bases cientificas, que pueden abonar a la formación de formadores y de investigadores

$\Rightarrow$ El docente que investiga y difunde sus resultados mejora su docencia

- Tiene más oportunidades de participar en el diseño educativo y no solo acatarlo acriticamente

\section{Fig. 8 Generación de productos de información docente y académica}

El derecho a la comunicación, en toda su amplitud, va más allá de las nociones de libertad de prensa como mecanismo de libre expresión de ideas, el acceso a la información pública y gubernamental y al ejercicio pleno de la diversidad y pluralidad de los medios y los contenidos. También cubre la producción y la compartición del saber, con el debido respeto a la vida privada y los derechos culturales, como la diversidad lingüística, la expresión abierta e irrestricta de creencias y de pensamiento. Como bien lo expresa Mattelart:

Resulta necesario imaginar nuevas formas de ciudadanía que deben ser conquistadas, en función de las necesidades de nuestro tiempo. Para que el derecho a la comunicación llegue a ser una parte indisociable de los derechos civiles y sociales, es necesario que se garanticen las condiciones políticas, económicas, sociales y culturales, que otorgan a los ciudadanos el poder de transformación y del cambio, para así poder perseverar, en su combate por el reconocimiento de su dignidad humana. El reconocimiento del derecho de todos, a participar en la transformación de la sociedad. (Mattelart, 2013, pág. 234)

\section{CONCLUSIÓN}

La construcción de ciudadanía y el fortalecimiento de la democracia pasan por el desarrollo de la competencia mediática, en relación estrecha con el resto de los ámbitos de la competencia comunicativa. Entre las posibles consecuencias de no mantener esta apuesta, se encuentra la de pasar por alto la impresición argumental, las imágenes engañosas, la pérdida de la memoria histórica ante lo apabullante e impactante de las noticias, cuya agenda se renueva con una velocidad abrumadora y en la cual se pierden piezas claves de información. Una de las consecuencias más graves es el descrédito y suspicacia hacia la información noticiosa.

El propósito, al incorporar de lleno a los medios en la composición de las secuencias didácticas que forman parte de la planeación de clases y asignaturas académicas, es marcar una pauta que pueda hacer hábito en los 
docentes y profesores del entorno y contexto educativo, que eventualmente conduzca a formas novedosas de entender y ejercer la democracia en las generaciones emergentes, porque interesa o debe interesar a los docentes de todos los niveles educativos, desde educadores de párvulos hasta profesores e investigadores universitarios y a los usuarios de los medios, implementar la forma tanto para hacer análisis como para diseñar acciones que permitan ampliar los espacios de oportunidad para observar y debatir, de manera conjunta, sobre el contenido de las informaciones, de su modo de producción, de las causas estructurales de los silencios y de las saturaciones, de los procesos de concentración de la empresas mediáticas, de la injerencia del poder político, de la reconfiguración del paisaje mediático, y de los efectos y consecuencias de la incorporación de las tecnologías digitales, así como sobre las maneras de formar a las nuevas generaciones.Conviene a todas luces impulsar desde la escuela el ejercicio de una ciudadanía activa, en una sociedad bajo el signo de la democracia participativa y verdaderamente corresponsable

[i] http://ec.europa.eu/avpolicy/media_literacy/consultation/index_en.htm.

[ii] www.aocmedialiteracy.org/index.php?

Itemid=1\&limit=10\&limitstart=10\&option=com_clearinghouse\&searchword=naciones\&task=searchgral\&type=\&type_search=All.

[iii] http://www.educadem.oas.org/boletin5/

[iv] http://www.unicef.org/magic/bits/espanol.html

[v] http://unesdoc.unesco.org/images/0021/002160/216099S.pdf

[vi] www.euromedialiteracy.eu.

[vii] www.unaoc.org.

[viii] http://es.slideshare.net/Engelnator/estudio-2013-de-hbitos?related=1

[ix] www.europarl.europa.eu/sides/getDoc.do?pubRef=-//EP//TEXT+REPORT+A6-2008-

$0461+0+\mathrm{DOC}+\mathrm{XML}+\mathrm{V} 0 / / \mathrm{ES}$

[x] http://ec.europa.eu/avpolicy/media_literacy/docs/recom/c_2009_6464_es.pdf.

[xi] http://www.ngpuebla.com/nota-sep-anuncia-creación-de-@aprendemx-81998.htmI\#.VDLN70EpjW8

[xii] El resaltado es nuestro

[xiii] Cursos masivos y abiertos en línea, ( Massive Online Open Courses; MOOC por sus siglas en inglés)

[xiv] http://www.eduteka.org/modulos/2/45/564/1

[xv] http://www.mundodehoy.com/index.php/salud/16591.html

\section{REFERENCIAS BIBLIOGRÁFICAS}

ACEVES, F.: "Poderes fácticos, comunicación y gobernabilidad: un acercamiento conceptual". Revista Mexicana de Ciencias Políticas y Sociales, 217, enero-abril de 2013.

AGUADED, J. I. (2013). La enseñanza obligatoria ante la competencia en comunicación audiovisual en un entrono digital. Memoria Técnica: Proyecto Coordinado: LA COMPETENCIA EN COMUNICACIÓN AUDIOVISUAL EN UN ENTORNO DIGITAL; DIAGNÓSTICO DE NECESIDADES EN TRES ÁMBITOS SOCIALES: LOS PROFESIONALES DE LA COMUNICACIÓN, LA UNIVERSIDAD Y LA EDUCACIÓN OBLIGATORIA. Huelva: España. 
AGUERRDONDO, I. (2009). Conocimiento complejo y competencias educativas. Retrieved 2013 йил 06-11 from UNESCO-IBE:

http://www.ibe.unesco.org/fileadmin/user_upload/Publications/Working_Papers/knowledge_compet_ibewpci_8.pdf

CHEVALLARD, Y. (1998). La transposición didáctica. Del saber sabio al saber enseñado. Obtenido de http://fba.unlp.edu.ar/metodologiadelasasigprof/tps/File_chevallard.pdf

CONTRERAS, J. H. (2006). MEDIOCRACIA, los medios que mecen la cuna. Chihuahua: IEECH.

CORTÉS, J. A., MARÍN, R., \& GUZMÁN, I. (2013). “Ámbitos y alcances de la competencia comunicativa en educación”. European Scientific Journal, 282-304.

CORTÉS, J., \& CARRILLO, L. E. (2012). "La competencia comunicativa en la producción académica”. En V.V.A.A., Evaluación de competencias docentes en educación superior (pp. 249-282). México: Juan Pablos Edits.

ECHEVERRÍA, V. M. (2014). "Representaciones de la pobreza en contextos de crisis, un ejercicio desde un análisis crítico del discurso". (U. Javeriana, Ed.) Signo y Pensamiento $N^{\circ} 64$, XXXIII(64), 78-94.

FERRÉS, J., \& PISTICELLI, A. (2012). "La competencia mediática: propuesta articulada de dimensiones e indicadores”. Comunicar. Revista Cientíca de Educomunicación. Nº 38 Vol. XIX, 75-82.

GABELAS, J., MARTA LAZO, C., \& HERGUETA C., E. (2012). "Comunicación, ubicuidad y aprendizajes”. Actas del IV Congrso Internacional Latina de Comunicación Social. Tenerife: SLCS - UL.

INEGI. (2013). Disponibilidad y uso de tecnologías de información en los hogares. Recuperado el 13 de agosto de 2014, de Instituto Nacional de Estadística y Geografía:

http://www3.inegi.org.mx/sistemas/microdatos/encuestas.aspx?c=34504\&s=est

JONNAERT, P., BARRETTE, J., MASCIOTRA, D., \& YAYA, M. (2008). "La competencia como organizadora de los programas de formación: Hacia un desempeño competente". Recuperado el 20 de enero de 2009, de Revista de currículum y formación del profesorado 12 (3): http://www.ugr.es/local/recfpro/rev123ART3.pdf

MANCINAS, R. (2008). El poder mediático en México: Relaciones entre economía, política y medios de comunicación. Sevilla: Ámbitos para la comunicación.

MARÍN, R., \& GUZMÁN, I. (2013). Proyectos formativos para el desarrollo de competencias. Chihuahua: UACH.

MATTELART, A. (2013). Por una mirada-mundo. Conversaciones con Michel Sénécal. Temuco, Chile:

Universidad de la Frontera.

MATTELART, A., \& MATTELART, M. (1997). Historia de las teorías de la comunicación. Barcelona: Paidos.

PAUL, R., \& ELDER, L. (2007). Lectura Crítica. (F. p. Crítico, Ed.) Recuperado el 12 de 05 de 2010, de Eduteka: http://www.eduteka.org/pdfdir/LecturaCritica.pdf

POPPER, K. (2006). La sociedad abierta y sus enemigos. Barcelona: Paidois Iberica.

RAMONET, I. (1998). La tiranía de la comunicación. Madrid: Temas de DEBATE.

REIG, R. (2004). Dioses y diablos mediáticos. Barcelona: URANO.

ROEGIERS, X. (2010). Pedagogía de la integración: Competencias e integración de los conocimientos en la enseñanza. México: Fondo de Cultura Económica.

SALAZAR, A. R., \& PARRA SANDOVAL, M. C. (2011). El pensaiento sociológico del siglo XIX al siglo XXI. Maracaibo: Universidad de Zulia.

SARTORI, G. (1997). ¿Qué es la democracia? México: Nueva Imagen. 
SARTORI, G. (2000). Teoría de la Democracia 1. El debate contemporáneo. Madrid: Alianza Ed.

UNESCO. (2011). Alfabetización mediática e informacional, curriculum para profesores. París: UNESCO.

ZABALA, A., \& ARNAU, L. (2007). 11 ideas clave de como aprender y enseñar competencias. Barcelona: GRAO.

Ámbitos. Revista Internacional de Comunicación, n.29, año 2015, tercer trimestre (verano).

Recibido: 24/06/2015

Aprobado: 19/07/2015 